\title{
Triangulation among Speech Language Pathologist, Deaf Educators, and Audiologists
}

Ye Wang

Missouri State Univeristy

Follow this and additional works at: https://bearworks.missouristate.edu/articles-chhs

\section{Recommended Citation}

Ye Wang "Triangulation among Speech Language Pathologist, Deaf Educators, and Audiologists." Journal of Communication Disorders, Deaf Studies \& Hearing Aids 1 no. 1 (2013).

This article or document was made available through BearWorks, the institutional repository of Missouri State University. The work contained in it may be protected by copyright and require permission of the copyright holder for reuse or redistribution.

For more information, please contact BearWorks@library.missouristate.edu. 


\section{Triangulation among Speech Language Pathologist, Deaf Educators, and Audiologists \\ Ye (Angel) Wang*}

Associate Professor, Communication Sciences and Disorders, Missouri State University, USA

Triangles, as common geometric forms, are considered sturdy and are widely used in construction for their natural strength. Triangulation, in social science, is defined as the mixing of multiple perspectives, data or methods to allow diverse viewpoints or standpoints deepen and widen our understanding on a topic. Journal of Communication Disorders, Deaf Studies \& Hearing Aids (JCDSHA), by default, is an interdisciplinary academic journal that supports triangular collaborations among Speech Language Pathologists, Deaf Educators, and Audiologists. What does this triangular collaboration mean and why should we bother? Or, in other words, what are the different types of triangulation and what are the advantages and disadvantages of triangulation?

To me, triangulation means at least five variations: investigator triangulation, theory triangulation, methodological triangulation, data triangulation and setting triangulation. Investigator triangulation manifests an evaluation team consisting of multiple investigators wherein each investigator examines the case/client from their own professional perspectives and the findings from each evaluator would then be compared and combined to develop a broader and deeper understanding of the case/client. Theory triangulation involves the validation of the findings from multiple disciplines, that is, Speech Language Pathology, Deaf Education, and Audiology. Methodological triangulation entails the use of multiple qualitative and/or quantitative methods to evaluate the case/client for developing treatment plans.
Data triangulation includes using different sources of information, some of which might be formal, some of which might be informal, in the evaluation process. And finally, setting triangulation means the use of different settings, such as location, time or day, to see if the findings are the same across various settings. The benefits of the various triangulations include increased confidence in the validity of the evaluation and a deeper and clearer understanding of the case/ client. On the other hand, triangulations might be time-consuming, that is, the diversity of the data collection requires greater organization and planning. Furthermore, investigators' professional biases and/or theoretical frameworks can cause conflicts and disharmony within the team.

In short, triangulation can be a useful interdisciplinary tool in maximizing the collaborations among Speech Language Pathologists, Deaf Educators, and Audiologists; however, its success relies on careful planning and mutual trust from all parties. Meanwhile, Open Access can be a means of accelerating the interdisciplinary collaboration by providing free and unrestricted access of information via the Internet. Interdisciplinary triangulation in JCDSHA seeks to synthesize broad perspectives, epistemology, knowledge, and skills in Speech Language Pathology, Deaf Education, and Audiology, which cannot be adequately understood from a single disciplinary perspective. It is an innovative way of thinking across multiple disciplinary boundaries to remedy the harmful effects of excessive specialization.
*Corresponding author: Ye (Angel) Wang, Ph.D, Associate Professor, Communication Sciences and Disorders, Missouri State University, USA, $901 \mathrm{~S}$ National Avenue, Springfield, MO 65897, Tel: 417-836-6347; Fax: 417-836-4242; E-mail: YeWang@MissouriState.edu

Received June 18, 2013; Accepted June 20, 2013; Published June 22, 2013

Citation: Wang Y (2013) Triangulation among Speech Language Pathologist, Deaf Educators, and Audiologists. Commun Disord Deaf Stud Hearing Aids 1 : e102. doi:10.4172/2375-4427.1000e102

Copyright: ( 2013 Wang Y. This is an open-access article distributed under the terms of the Creative Commons Attribution License, which permits unrestricted use, distribution, and reproduction in any medium, provided the original author and source are credited. 